\title{
Endogenous regulation of 11-deoxycorticosterone (DOC) and corticosteroid receptors (CRs) during rainbow trout early development and the effects of corticosteroids on hatching.
}

\author{
Kiilerich Pia ${ }^{1}$, Geffroy Benjamin ${ }^{1}$, Valotaire Claudiane ${ }^{1}$, Prunet Patrick ${ }^{1,{ }^{*}}$
}

${ }^{1}$ INRA, UR 1037, Laboratoire de Physiologie et Génomique des Poissons, IFR140, Campus de

Beaulieu, F-35042 Rennes Cedex, France

* Corresponding author : Patrick Prunet, email address : patrick.prunet@rennes.inra.fr

\begin{abstract}
:
Clear evidence for a physiological role of the mineralocorticoid-like hormone 11-deoxycorticosterone (DOC) and the mineralocorticoid receptor (MR) in fish is still lacking. Efforts to demonstrate an osmoregulatory role for this hormone has so far not been conclusive, while a few scattered studies have indicated a role for DOC in development and reproduction. In this study, we investigate the onset of de novo DOC synthesis in parallel with endogenous corticosteroid receptor mRNA production from fertilization to the swim-up stage in rainbow trout. Whole egg DOC content decreased from fertilization until hatching followed by an increase to pre-fertilization levels just after hatching. Onset of de novo transcription of corticosteroid receptor mRNA's was observed shortly after the midblastula transition; initially glucocorticoid receptor 2 (GR2) followed by MR and then GR1. Non-invasive introduction of DOC or cortisol at fertilization resulted in altered corticosteroid receptor regulation and accelerated hatching date, suggesting a regulatory role in trout ontogenesis of both hormones through MR signaling pathway. The results presented in this study suggest a possible physiological role of the DOC-MR signaling pathway during fish ontogenesis, at fertilization and just after hatching.
\end{abstract}

\section{Highlights}

- Large amount of DOC deposited in rainbow trout eggs. Onset of de novo DOC synthesis in the trout egg just after hatching. Onset of de novo CRs transcription (GR2<MR<GR1) shortly after midblastula transition. Cortisol and DOC treatments accelerate hatching date. Cortisol and DOC treatments affect regulation of GR1, GR2 and MR.

Keywords : 11-deoxycorticosterone Cortisol Mineralocorticoid receptor Glucocorticoid receptor Fish Development 


\section{Introduction}

Corticosteroids are a group of cholesterol-derived hormones regulating metabolism, ion homeostasis, and the stress response during the life-span of animals. From their function in tetrapods, corticosteroids are divided in two subgroups; glucocorticoids (cortisol and corticosterone) which govern regulation of growth, metabolism, immune function, behaviour and stress (Mommsen et al. 1999; Young et al. 2004) and mineralocorticoids (aldosterone), which regulates not only hydromineral balance, but also cardiovascular remodelling, fat storage, energy balance and behaviour (reviewed in Viengchareun et al., 2007). This clear division of tasks does not seem to apply to teleost fish, where the absence of aldosterone (Balment and Henderson 1987; Jiang et al. 1998) seemingly leaves cortisol with both the glucocorticoid and the mineralocorticoid functions described in tetrapods. It is well-established that cortisol, besides regulation of classical glucocorticoid tasks, also governs osmoregulatory functions in fish (reviewed by McCormick, 2001). However, the recent identification of a mineralocorticoid receptor (MR) and its potential physiological ligand in fish, 11-deoxycorticosterone (DOC) might reveal a more complicated corticosteroid signaling axis than previously expected (Prunet et al., 2006). Thus, the MR signaling pathway has been suggested to be involved in brain-dependent behavioural and visual responses and also the stress responses (Sakamoto et al., 2016; Kiilerich et al., 2017) but largely not in osmoregulatory functions (McCormick et al., 2008; Takahashi and Sakamoto, 2013; Sakamoto et al., 2016) although conflicting literature exists (Kiilerich et al., 2011a,b,c).

Besides regulation of the important physiological processes described above, cortisol also participates in regulation of major developmental changes. This was initially shown in metamorphosis of larval stages in flounder (de Jesus et al. 1990; de Jesus et al. 1991) and preadaptive development of saltwater tolerance in juvenile salmon (Mommsen et al. 1999). More recently, the role of cortisol has been highlighted in the metamorphosis of eels (Rousseau et al. 
2008) and skin ionocyte ontogenesis in zebrafish embryos (Cruz et al., 2013; Trayer et al., 2013). Furthermore, Morpholino knock-down of the glucocorticoid receptor (GR) in zebrafish, demonstrate decisive roles of the cortisol-GR axis during embryonic development. The dramatic developmental defects of GR knock-down induced severe malformations of neural, vascular, and visceral organs (Pikulkaew et al., 2011; Nesan et al., 2012). Moreover, increased concentration of cortisol in newly-fertilized eggs caused disruption in cardiogenesis (see review by Nesan and Vijayan, 2012). Taken together, these findings support a major role of cortisol during the developmental program of fish through the GR signaling pathway. In salmonids, artificial elevation of cortisol levels in eggs, either pre- or post-fertilization, has long-lasting consequences on stress responsiveness, behaviour, metabolic physiology, morphology and survival of fry (Eriksen et al., 2007, Auperin and Geslin, 2008, Sloman, 2010; Colson et al. 2015), which may occur through early unknown developmental effects although little is known regarding the signaling pathways.

DOC and MR are also involved in many different physiological processes. For instance, DOC and MR have been associated with spermiation and oocyte maturation in several fish species (reviewed by Milla et al. 2009) and precocious hatching in medaka (Cloud, 1981), t hus linking the mineralocorticoid axis in fish to reproduction and development. However, contrarily to cortisol action, attempts to demonstrate an involvement of MR signaling pathway in ionocyte ontogenesis at the level of skin have been unsuccessful, thus supporting a lack of osmoregulatory role (Cruz et al., 2013; Trayer et al., 2013). Despite these first reports, we are far from having a clear idea of the physiological and developmental roles of the DOC/MR signaling axis.

To examine the contribution of the two corticosteroid (DOC and cortisol) signaling axes in the regulation of embryonic development in rainbow trout, we initially describe the endogenous content of DOC and compare this with the regulation of corticosteroid receptor (CR) transcript levels from fertilization to the fry-stage. Furthermore, we examine the effect of an early increase in DOC and 
cortisol levels on gene regulation and hatching. We use the natural uptake of water just after fertilization to transiently boost the cortisol and DOC levels in rainbow trout eggs in a non-invasive manner. Consequences of these hormonal treatments were analysed at the level of endogenous corticosteroid receptor mRNA regulation and by observation of various developmental parameters such as hatching date, egg and fry mortality and the number of malformations. 


\section{Materials and Methods}

\section{$\underline{2.1 \text { Eggs and fertilization }}$}

Eggs and sperm were gently stripped from sexually mature female and male rainbow trout (Oncorhyncus mykiss) under anaesthesia (0.05\% 2-phenoxyethanol) either at the INRA-LPGP fish facility or at the INRA/SEDI fish farm (Sizun, France) and subsequently transported on ice to INRA-LPGP facility. For each experiment a pool of eggs and sperm were obtained from several female and male rainbow trout and fertilized at $10{ }^{\circ} \mathrm{C}$ for 30 min- 1 hour in ActiFish ${ }^{\circledR}$ (IMV, L'Aigle, France) with or without hormones (i.e. control, DOC or cortisol, see below for a descriptive protocol). Fertilized embryos were subsequently divided into an appropriate number of incubators $(10 \mathrm{~cm} \times 10 \mathrm{~cm})$ supplied with $10{ }^{\circ} \mathrm{C}$ flow-through re-cycled facility water until the end of the experiment. Sampled eggs were quickly frozen and stored at $-80{ }^{\circ} \mathrm{C}$ while fry were euthanized with an overdose of 2-phenoxyethanol before sampling and stored at $-80{ }^{\circ} \mathrm{C}$.

\subsection{Total embryo DOC content and corticosteroid mRNA during development:}

From a total of $\sim 5000$ fertilized eggs distributed in 4 incubators, 8 pools of 10 eggs (or fry) were randomly sampled for RNA extraction, at each time-point. Ten pools of 20 eggs (or 15 fry)were also sampled at each time-points for DOC extraction. Fry were euthanized with an overdose of 2phenoxyethanol before sampling to avoid stress effects on the measured parameters. Sampling time-points were as follows: 1 and 17 hour post fertilization (hpf) and 1, 2, 3, 6, 10, 14, 17 (eyed stage), 20, 27, 34 (hatching), 44, 48 and 55 (swim-up stage) day post fertilization (dpf).

\subsection{Effect of cortisol and DOC on hatching and CR mRNA regulation during development:}

4000 eggs from 3 different females were collected in a glass beaker before adding a mix of sperm from 2 different males. After 5 minutes incubation $500 \mathrm{ml}$ incubation medium $\left(100 \mathrm{ml} \mathrm{Actifish}{ }^{\circledR}+\right.$ 
$400 \mathrm{ml}$ water) containing $55 \mu \mathrm{M}$ cortisol or DOC (final concentration) or ethanol vehicle (control, final concentration $0.4 \% \mathrm{EtOH}$ ) was added and the fertilized embryos left to take up water and hormone for 30 minutes. This dose of corticosteroids was chosen from a pilot experiment where this was the lowest dose which accelerated hatching. Levels of DOC and cortisol were measured in the eggs between treatment and hatching, ranging respectively from 1000 to $136 \mathrm{ng} / \mathrm{g}$ body weight and from 440 to $342 \mathrm{ng} / \mathrm{g}$ body weight (data not shown). These hormonal treatments led to a 1000 and 50-100 fold increase in DOC and cortisol levels, respectively, compared to non-treated eggs. The differences in cortisol and DOC levels in eggs after a similar treatment may be related to lower polarity of DOC of which uptake by eggs should be greater when compared to cortisol. Finally, this dose is lower than the dose $(100 \mu \mathrm{M})$ used for treating zebrafish embryos by bathing them with synthetic glucocorticoids (Wilson et al., 2013, 2016) and less than that shown to have morphological effects in zebrafish (Hillegass et al., 2008). Eggs from each treatment group were washed several times in facility water before distributing each group in 4 separate incubators for each treatment supplied with flow-through recycled facility water. At $1 \mathrm{hpf}, 1,2,3,6,10,14,17,20$, 27, 34, 44, 48 and 55 dpf the number of dead embryos was recorded and removed from the incubators. At 1 hpf, 1, 2, 3, 6, 10, 14, 17, 20, and 27 dpf 6 pools of 10 eggs were sampled for total RNA extraction. A detailed survey of the number of hatched embryos was conducted every day from day 27 to day 37 after fertilization. At the swim-up stage ( $55 \mathrm{dpf})$ fry were euthanized with an overdose of 2-phenoxyethanol before counting and visual determination of malformations. Malformations were categorized in groups representing yolk sac resorption defects (YSD), crooked body, small size, cyclopia, prognathia, tail absence, siamese, albino or miscellaneous bodily malformations according to Bonnet et al. (2007) and expressed as a percentage of fry alive at day 55.

\subsection{Analyses:}




\subsubsection{Hormone extraction and DOC measurement}

For DOC extraction 20 eggs or 15 larvae were homogenized in $750 \mu$ water using a T18 ULTRATURRAX homogenizer (IKA-WERKE, Staufen, Germany) followed by 3 freeze-thaw cycles. Recovery of steroids from the eggs was assessed by addition of $4000 \mathrm{cpm}{ }^{3} \mathrm{H}$-DOC (American Radiolabelled chemicals, St Louis, MO, USA) to the homogenate. Samples were kept at $-80{ }^{\circ} \mathrm{C}$ until all the samples were ready for extraction. For extraction of steroids samples were kept for 2 hours at room temperature to ensure full thawing of the samples before adding $2 \mathrm{ml}$ ethylacetate/cyclohexane $(50 / 50, \mathrm{vol} / \mathrm{vol})$. The supernatant was removed after freezing at $-20{ }^{\circ} \mathrm{C}$ for at least 1 hour followed by another round of ethylacetate/cyclohexane extraction. After ethylacetate/cyclohexane evaporation, extracted steroids were re-dissolved in $60 \mu 1$ ethanol. 50 $\mu 1$ of the steroid-ethanol solution were injected in a HPLC column (Agilent, Massy, France) and passed through a mobile phase containing acetonitrile/water $(80 / 20, \mathrm{v} / \mathrm{v})$ acidified with $0.01 \%$ sulphuric acid. The collected organic chromatographic elution fractions were evaporated to dryness and redissolved in $250 \mu \mathrm{l}$ assay buffer $\left(0.01 \mathrm{M} \mathrm{NaH}_{2} \mathrm{PO}_{4}, 0.01 \mathrm{M} \mathrm{Na}_{2} \mathrm{HPO}_{4}, 0.9 \% \mathrm{NaCl}\right.$, and $0.1 \%$ gelatine, $\mathrm{pH}$ 7.25). The recovery of steroids was assessed by measurement of ${ }^{3} \mathrm{H}-\mathrm{DOC}$ in $40 \mu \mathrm{l}$ of re-dissolved chromatographic fraction with $100 \mu \mathrm{l}$ ethanol in $2.5 \mathrm{ml}$ scintillation liquid on a TriCarb 2100 TR Liquid Scintillation Analyzer (Packard or Perkin-Elmer) resulting in an average recovery of steroids at $24.8 \% \pm 60 \mathrm{SD}$. The low recovery rate was most likely due to a significant but unavoidable formation of an insoluble vitellogenin-ethylacetate/cyclohexane solid phase containing some of the steroids. Thus, the recovery rate for ${ }^{3} \mathrm{H}$-DOC in each individual sample was used to calculate the endogenous DOC content in the same sample. Measurement of DOC was done in duplicates using a RIA assay as previously described (Kiilerich et al. 2011c).

\subsubsection{Cortisol measurement}


Extraction and measurement of cortisol were carried out as described by Auperin and Geslin (2008). Recovery of cortisol was assessed with ${ }^{3} \mathrm{H}$-cortisol using a similar protocol as for DOC and was estimated to $69 \% \pm 12 \mathrm{SD}$. As this parameter was quite stable between samples, we did not adjust each individual sample for cortisol recovery rate.

\subsubsection{RNA extraction and $q P C R$}

The 10 eggs collected at each time-point were homogenized in $4 \mathrm{ml}$ TRIzol (Invitrogen, Carlsbad, CA, USA) and RNA extracted using a high-salt precipitation step according to manufacturers' recommendations. Concentration and purity of the RNA was assessed using A260/A280 and A260/A320 measurements on a Nanodrop device (Thermo Scientific, Wilmington, DE, USA). RNA quality was assessed on selected samples using a BioAnalyzer (Agilent Technologies, Santa Clara, CA, USA). $1.5 \mu$ g RNA were subjected to DNase treatment (0.5 units RQ1 DNase (Promega) per sample incubated at $37^{\circ} \mathrm{C}$ for $30 \mathrm{~min}$ ) before it was used for cDNA synthesis with $1 \mu \mathrm{g}$ random primers (Promega, Madison, WI, USA), $0.5 \mathrm{mM}$ dNTPs (Promega), 200 units MMLV reverse transcriptase (Promega) in the presence of 25 units RNasin (Promega) in a total volume of $25 \mu 1$. After denaturation of the RNA at $70{ }^{\circ} \mathrm{C}$ for $5 \mathrm{~min}$, reverse transcription (RT) conditions were $30{ }^{\circ} \mathrm{C}$ for $10 \mathrm{~min}, 37^{\circ} \mathrm{C}$ for 1 hour and $95^{\circ} \mathrm{C}$ for $10 \mathrm{~min}$. RT reactions were randomly distributed in two 96 well plates and diluted 3 times in water to a total volume of $75 \mu 1$ after completion of the cDNA synthesis. For qPCR $1 \mu$ diluted cDNA were added to $10 \mu$ Fast SYBR ${ }^{\circledR}$ Green Master mix (Applied Biosystems, Carlsbad, CA, USA), $250 \mathrm{nM}$ forward and $250 \mathrm{nM}$ reverse primer in a total volume of $20 \mu \mathrm{l}$. Cycling conditions were $95{ }^{\circ} \mathrm{C}$ for 20 seconds followed by 40 cycles of $95{ }^{\circ} \mathrm{C}$ for 3 seconds and $60^{\circ} \mathrm{C}$ for 30 seconds on a Step-One Plus real-time PCR machine (Applied Biosystems, Carlsbad, CA, USA). Melting curve analysis was routinely carried out for each qPCR run with 0.3 ${ }^{\circ} \mathrm{C}$ intervals from 65 to $90{ }^{\circ} \mathrm{C}$. 


\subsubsection{Normalization, amplification efficiency and absolute quantification}

18S rRNA was used as normalization gene using $1 \mu \mathrm{l}$ of 1/1000 diluted cDNA with identical QPCR conditions as described above. Amplification efficiency was determined on each plate for each primer-set. $2 \mu$ undiluted cDNA from each sample were pooled and diluted 2, 4, 8, 16 and 32 times in duplicates. For $18 \mathrm{~S}$ rRNA a dilution series of 500, 1000, 1500 and 2000 was used. The Pfaffl equation was used to calculate the relative copy number of the target and normalization genes and normalized values were obtained by dividing the relative levels of the target gene with the relative levels of the normalization gene.

An absolute quantification of GR1, GR2 and MR primers were previously described in Kiilerich et al. (2011c) allowing a direct comparison of mRNA levels among these three primer-sets.

\subsubsection{Primers}

To ensure specific detection of GR1, GR2 and MR primers were designed against the A/B-domain and the QPCR product were subjected to gel electrophoresis to verify amplification of only one PCR product. Primer sequences (5'-3') are as follows: GR1 forward: CCATCGTCAAGCGGGAAGAG， GR1 reverse: GGAACTCCACGCTAAGGGATTTATTC (GenBank Ace. No. Z54210), GR2 forward: CTCCGCTTTCTCCAGCAGCTA, GR2 reverse: GTGAGCCACCCCGTAGTGACAG (GenBank Acc. No. AY495372), MR forward: GAAACAGATGATCCGCGTGGT, MR reverse: TGGATCAGGGTGATTTGGTCCT (GenBank Acc. No. AF209873), 11ß-hydroxysteroid dehydrogenase 2 forward: AAGGGACGCATCGTCACAATCT, 11ß-hydroxysteroid dehydrogenase 2 reverse: AACAGGTTGAGAGCTGCCTTGG (GenBank Acc. No. AB104415), StAR forward: ACATGGAGCAGATGGGAGAC, StAR reverse: GCACAGCGAACACTAACGAA, (GenBank

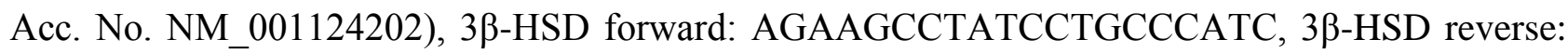


CATGTCCCTCTGAGCCCTCCG, (GenBank Acc. No. S72665), CYP21 forward: CGTGTCTCTATGGGGCTCTC, CYP21 reverse: GGCTTCCTCTGATGTTTTGC, (GenBank Acc. No. EU246942), 18S rRNA forward: CGGAGGTTCGAAGACGATCA, 18S rRNA reverse: TCGCTAGTTGGCATCGTTTATG (GenBank Acc. No. AF309412). All primers were purchased from Sigma-Aldrich, St. Louis, MO, USA.

\subsubsection{Statistical analysis}

Whole-egg DOC content and QPCR data on natural variations in CR's and corticosteroid synthesis enzymes were analyzed with a one-way ANOVA followed by multiple t-tests with Bonferroni correction. Effects on hatching date was analysed using a loglogistic model (similarly to Geffroy and Simon, 2013):

$$
y=0+[(1-0) /[1+\exp (b(\log (x)-\log (e))]],
$$

where $b$ is the slope of the curve around the point $\mathrm{f}$ inflexion (e); $e$ is the time required to reduce hatching by $50 \%$ (HT50; i.e. point of inflexion); $x$ is the time and $y$ is the response (hatching). The HT50 determined by the equation allowed comparing curves while considering all replicates within each treatment group, at each time. Data were then compared using a Wilcoxon test, and $p$ values were adjusted using the Holm method.

The regulation of corticosteroid receptors after hormone treatment were analyzed with two-way ANOVAs (with treatment and time as factors) followed by Bonferroni corrected pairwise comparisons at each time-point. Differences were considered significant when $\mathrm{p}<0.05$. Statistical analyses were carried out using Prism 4.03 (GraphPad Software Inc., La Jolla, CA, USA). Hatching time modelling was done using the add-on package adrc (Ritz and Streibig, 2005) of the R software (R Development Core Team 2009). 


\section{Results}

\section{$\underline{3.1 \text { Whole embryo corticosteroid synthesizing capacity during early development }}$}

Endogenous production of DOC from its cholesterol precursor is dependent on transcription, translation and activity of a subset of proteins involved in the steroid synthesis, specifically

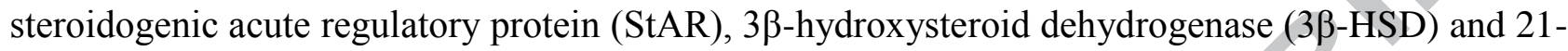
hydroxylase (CYP21). qPCR analyses of these three enzymes show that the capacity to synthesize DOC is present before hatching, at least at the transcript level (fig. 1). While there is a steady increase from fertilization to hatching, interrupted only by a sharp peak at $17 \mathrm{dpf}$ (emergence of eyed eggs) of $3 \beta-H S D$ and CYP21 (fig. 1B, C) mRNA levels, the regulation of StAR appears different (fig. 1A). Maternal StAR transcripts are maintained at the fertilization level until the onset of endogenous transcriptional activity at the midblastula transition (MBT, 2dpf), whereafter the mRNA level significantly decrease until it becomes undetectable by qPCR at $10 \mathrm{dpf}$. Endogenous StAR mRNA transcription was initiated just after the eyed stage and increased onwards to the swim-up stage.

\section{$\underline{3.2 \text { Corticosteroid receptors and 11 } 1 \text {-HSD2 mRNA levels during embryonic development }}$}

At $1 \mathrm{hpf}, \mathrm{GR} 2$ is the highest expressed CR compared to GR1 and MR, while the latter are expressed

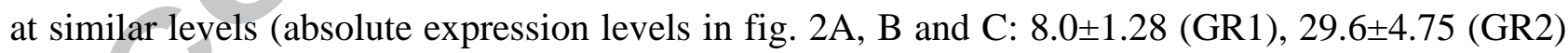
and 7.1 $\pm 0.94(\mathrm{MR}) \mathrm{p}<0.0001)$. GR2 is the first CR transcript to be endogenously transcribed, just after the midblastula transition (MBT) around 2 days post fertilization (dpf, fig. 2C), although the difference is significant only at $17 \mathrm{dpf}$. A maximum of a four-fold induction compared to 1 hpf is reached at $17 \mathrm{dpf}$ at the eyed stage, after which the GR2 level decreases and stabilizes at a lower level throughout the rest of the time-course (figure $2 \mathrm{C}$ ). $\mathrm{MR}$ is the second $\mathrm{CR}$ to be de novo transcribed in the eggs: There is an initial pronounced increase in egg MR content between 3 dpf 
and $10 \mathrm{dpf}$ after which the MR level steadily increases towards a 13.5-fold expression level at 48 dpf as compared to $1 \mathrm{hpf}$ - one week before total yolk-sac resorption (fig. 2A). Finally, GR1 transcription is initiated after $10 \mathrm{dpf}$, and becomes significantly different from the basal level (roughly between $1 \mathrm{hpf}$ and $10 \mathrm{dpf}$ ) at the eyed egg stage at $17 \mathrm{dpf}$ (fig. 2B). After a minute decrease, GR1 levels increase again from hatching to $48 \mathrm{dpf}$, reaching a maximum of an 8 -fold

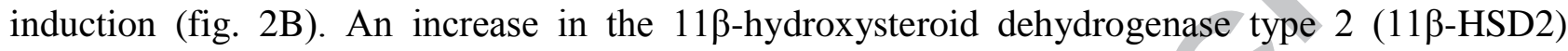
enzyme mRNA occurs just before hatching, between 27 and $34 \mathrm{dpf}$, and steadily increases towards $55 \mathrm{dpf}$ at the swim-up stage (fig. 2D).

\subsection{Whole embryo DOC content from fertilization to hatching stage}

High levels of DOC were present in the eggs just after fertilization (131 pg/egg, fig. 3). From fertilization until hatching a slow and constant decrease in whole embryo DOC content, reflecting usage and/or breakdown of maternal DOC, was observed. After reaching the lowest level at day 34 (45 pg/egg just immediately before hatching), a significant increase and a peak in DOC content (up to $271 \mathrm{pg} / \mathrm{egg}$ just after hatching) is followed by a stabilization of the DOC level (at $173 \mathrm{pg} / \mathrm{egg}$ ) towards the swim-up stage (fig. 3).

3.4 Early incubation with cortisol and DOC affect gene expression and hatching date of rainbow $\underline{\text { trout eggs }}$

Treatment of eggs with DOC or cortisol at fertilization affected the transcript levels of all three corticosteroid receptors. Interestingly, the effect was not observed immediately after treatment, but first from day 14 to 27 post fertilization (figure 4) for both treatments. DOC treatment resulted in an up-regulation of MR and GR1 levels at 20 and 27 dpf (figure 4A, B), but a down-regulation of GR2 levels at $14 \mathrm{dpf}$ followed by up-regulation at 17, 20 and $27 \mathrm{dpf}$ (figure 4C). Cortisol caused up- 
regulation of MR, GR1 and GR2 levels at $27 \mathrm{dpf}$ and a down-regulation of MR at $14 \mathrm{dpf}$. The effect of DOC was only significantly different from that of cortisol at $20 \mathrm{dpf}$ for all three CR transcripts. The early boost of egg hormone content did not affect wet weight of the eggs and fry, the mortality during the sampling time-course (not shown) nor the number of malformed fry at the end of the experiment at $55 \mathrm{dpf}$ (fig. 5A). Fry malformations were visually assessed and categorized into 9 groups, where yolk sac resorption defects (YSD), torsions of the body, and prognathia were the most frequent. Miscellaneous bodily malformations were grouped together with other relatively rare malformations such as small size, cyclopia, tail absence, siamese and albino.

Both DOC and cortisol treatment at fertilization significantly accelerated hatching (HT50 DOC: 31.47 vs Control: 32.16 , p-value $=0.02$; HT50 Cortisol: 31.87 vs Control: 32.16 , p-value $=0.03$ fig. 5B). Furthermore, DOC treatment also tended to result in accelerated hatching when compared to cortisol treatment ( $\mathrm{p}$-value $=0.06$, fig. 5B). 


\section{Discussion}

The aim of this study was to describe and investigate the roles of the corticosteroid signaling system in rainbow trout embryonic development in order to clarify the role of the mineralocorticoid-like axis, DOC and MR. A detailed time-course study of the corticosteroid signaling elements is presented during rainbow trout early development from fertilization to the swim-up stage on the level of mRNA transcription of MR, GR1, GR2 and 11 $\beta$-HSD2, along with the protein involved in DOC synthesis, i.e. StAR, 3 $\beta$-HSD and CYP21 and onset of de novo synthesis of DOC. Overall, these data support the involvement of cortisol and GR signaling axis in trout early development and suggest that the MR/DOC system may also play a role during embryonic development, although the functional role of this system still remain to be clarified. The effect of exogenous corticosteroids (cortisol or DOC) on regulation of the corticosteroid receptors (GR1, GR2 and MR) and timing of hatching bring some new elements of response regarding the role of both cortisol and DOC.

\section{$\underline{4.1 \text { Role of DOC in rainbow trout early development }}$}

Here we show, for the first time in fish, the course of whole egg DOC content from fertilization to the swim-up stage. First of all, a large amount of maternal produced DOC is deposited in the eggs before ovulation, which is then gradually broken down during the early parts of embryogenesis to reach as low a level as $\sim 4.5 \mathrm{pg} /$ individual just before hatching. Interestingly, a $\sim 60$-fold increase in whole egg DOC levels - reaching fertilization levels - is seen just after hatching and sustained until the swim-up stage. Based on the regulation of DOC synthesis enzymes, StAR, 3 $\beta-$ HSD and 21hydroxylase de novo DOC synthesis is possible from day 20 post fertilization, however DOC levels first increase between day 34 to 44 - coincident with hatching. Since these enzymes are also involved in cortisol synthesis pathway, the ability of this enzymatic system to be involved in 
cortisol production in trout eggs has also to be considered. Actually, Auperin and Geslin (2008) have observed a decrease in whole body cortisol level from fecundation until eyed stage but followed by an increase in cortisol levels in trout eggs at $27 \mathrm{dpf}$ indicating capability of eggs to synthetize this corticosteroid at least 6 days before hatching. Such picture observed in rainbow trout embryo-larvae stages appeared significantly different from what has been reported in zebrafish where both cortisol levels and steroidogenic enzyme gene expressions increased after hatching (Alsop and Vijayan, 2008). Our data on DOC levels during embryogenesis suggest that DOC may be important not only during early development in trout embryos but also after hatching in relation with the organization of aquatic life.

\subsection{Regulation of the corticosteroid receptors}

The detailed time-course conducted here show differential regulation of the three corticosteroid receptors, MR, GR1 and GR2, in parallel with 11 $\beta$-HSD2 during trout embryonic development. Based on the chronology of which the CR's are de novo transcribed, GR2 (at $3 \mathrm{dpf}$ ) and MR (at 6 dpf) are suggested to be important transcription factors in the very early parts of embryogenesis just after mid-blastula transition, whereas this is probably not the case for GR1 (17 dpf). These early changes in GR2 and MR expression also correlates with high DOC and cortisol levels as previously discussed. Additionally, the higher GR2 mRNA level compared to GR1 and MR suggest that GR2 is the most important glucocorticoid receptor during the developmental time-course presented here, especially at the beginning of de novo transcription at the MBT and emergence of eyed eggs. However, while GR2 exhibits the highest expression level at fertilization, a greater fold increase of MR during the days following mid-blastula transition suggests some importance of signaling through this receptor as well. Altogether, these data support the role of cortisol and GR signaling in developmental programming and suggest that the MR signaling pathway may also be involved in 
the regulation of these biological processes in rainbow trout. These conclusions based on measurements of mRNA abundance should be confirmed by measurement of protein levels.

The increase in corticosteroid receptor (GR and MR) levels during embryonic development has also been investigated in other fish species. An overall up-regulation of MR from fertilization until hatching has been observed in zebrafish (Alsop and Vijayan, 2008; Pikulkaew et al. 2010) but not in medaka (Trayer et al., 2013). Concerning GR expression in fish embryos, various contradictory patterns have been described in the literature: In zebrafish where a single GR has been identified (Schaaf et al. 2008), a decrease from fertilization until hatching was followed by an increase in GR mRNA levels until the feeding stage (Alsop and Vijayan 2008; Pikulkaew et al. 2010). In medaka where 2 GR forms have been described (Kim et al., 2011), a similar decrease of GR1 and GR2 transcript levels within 36 hours after fertilization has been observed by Trayer et al. (2013). This is somewhat discrepant with what has been reported in the present study on trout. On the other hand, the up-regulation of GR1 in trout eggs around the eyed stage does not coincide with the upregulation of GR1 after hatching in sea bass (Pavlidis et al. 2011), and is directly contradictory to a decrease described in tilapia (Tagawa et al. 1997). Concerning GR2, the up-regulation of mRNA levels at the midblastula transition (MBT) was not observed in sea bass, where there was no significant regulation of GR2 mRNA from the embryo to the juvenile stage (Pavlidis et al. 2011). Variations between these studies and the present study most likely reside in species specific developmental differences and/or differences in sampling time-points.

\section{$\underline{4.3 \text { Physiological role of the corticosteroid signaling systems }}$}

Presence of DOC and its mineralocorticoid receptor mRNA at significant levels in trout eggs suggests that the mineralocorticoid signaling system is active during embryogenesis and may be involved in regulation of developmental processes in rainbow trout. Moreover, our data also 
support the perception that glucocorticoid signaling (cortisol/GR1, cortisol/GR2) is involved in such regulation, in agreement with previous studies conducted in zebrafish (Pikulkaew et al., 2011; Nesan and Vijayan, 2012). With whole egg DOC levels ranging between 0.2-6.5 nM (volume of an average trout egg is $62.77 \pm 14.49 \mathrm{~mm}^{3}$ (Bonislawska et al. 2001)) and an MR EC 50 value of $0.1 \mathrm{nM}$ (Sturm et al. 2005), activation of MR by DOC is theoretically possible at all stages of development, assuming that the hormone is equally distributed in the egg with no compartmentalization.

However, based on the respective affinities of cortisol and DOC for MR (Sturm et al., 2005), one could anticipate that DOC may be competing with cortisol for MR binding as both hormones are present in the egg at the same time. DOC activation of MR is possible when cortisol levels are less than 10-fold compared to DOC, since MR has a 10-fold lower $\mathrm{EC}_{50}$ value for DOC than cortisol (Sturm et al. 2005) - at least in vitro. When comparing cortisol (Auperin and Geslin, 2008) and DOC (present study) concentrations in trout eggs, we find 3-4 times less DOC than cortisol between fertilization and day 20 whereas this ratio increase from day 27 until hatching on day 34 . Finally, after hatching this ratio decreases to 3-6 fold difference because of a large increase in DOC levels on day 44 and later. These data may suggest that DOC could be important during the first phases of embryogenesis and in the late phases before hatching. Interestingly, another important factor also to be considered is de novo transcription of the MR-protective enzyme 11 $\beta$-HSD2, which is responsible for cortisol degradation and most likely ensure DOC signaling through MR in the presence of cortisol. Our data on 11ß-HSD2 expression from the present study (fig.2) suggest that this enzyme activity may only be present just after hatching and later, coinciding with increase in cortisol levels (Auperin and Geslin, 2008) but also with a large increase in DOC levels (present study). This supports a possible role of the DOC-MR axis in the regulation of development after hatching. Such hypothesis has already been suggested by Alsop and Vijayan (2008) for regulation of zebrafish embryogenesis. Overall, these results suggest a possible involvement of DOC-MR 
pathway in the regulation of early embryogenesis and later during the larval development phase. Regarding glucocorticoid receptors the relatively low concentrations of cortisol in the egg (ranging from 10-25 nM (Auperin and Geslin, 2008)) favor cortisol signaling through GR2 compared to GR1 (EC 50 value: 0.7 and $46 \mathrm{nM}$, respectively (Bury et al. 2003)). This is consistent with the very early up-regulation of GR2 after the MBT and a significantly higher mRNA level of this receptor compared to GR1. However, it is worth noting that the increase in GR1 mRNA from hatching at 34 dpf to $48 \mathrm{dpf}$ (one week before complete yolk sac resorption) is coincident with emergence of a functional HPI-mediated stress-response in rainbow trout (Auperin and Geslin, 2008), suggesting GR1 may somehow partake in establishment and maturation of a stress-responsive feedback mechanism in the developing larvae.

\subsection{Effect of increased cortisol and DOC on hatching}

The possible role of DOC and cortisol on hatching was investigated by transiently boosting the in ovo corticosteroid levels at fertilization Despite the very large increase in cortisol $(\sim 7.5$ fold $)$ or DOC (from $\sim 150$ to $\sim 20$ fold) after treatment at fertilization which stay high until hatching, we did not see any morphological defects or increases in mortality after treatment. This is in agreement with previous studies where rainbow trout eggs transiently exposed to cortisol around fertilization did not induce detectable developmental defects (Auperin and Geslin, 2008; Sloman, 2010; Li et al. 2010). Higher doses of synthetic corticosteroid (dexamethasone) have also been used in zebrafish without inducing gross morphological defects (Wilson et al., 2013, 2016). However, the method used to treat fish eggs is important as other studies have shown significant morphological developmental defects after exposure to either pharmacological high cortisol levels (Li et al. 2010) or chronic cortisol treatment (Hillegass et al. 2008) probably reflecting abnormal activation/inactivation of the cortisol-GR signaling system. 
Our data not only confirm the accelerating effect of cortisol treatment on hatching but show that DOC has similar effect. As we did not observe similar levels of DOC and cortisol in eggs following the same treatment, it is difficult to extrapolate if one corticosteroid is more efficient or not compared to the other. This interesting observation lead us to suggest that the MR signaling system is probably involved in this effect of both corticosteroid hormones as DOC cannot activate GR receptors (Bury et al., 2003). However, as low levels of DOC have been observed at hatching (see figure 3), we suggest that cortisol is probably the corticosteroid which binds and activates MR at that period. The acceleration of hatching in trout eggs after DOC treatment observed in the present study is in agreement with one previous study in medaka, where DOC treatment during egg development resulted in a decrease of hatching time regardless of the time of DOC exposure $(0,4,8$ dpf, Cloud, 1981). This led the author to suggest that DOC probably induced precocious release of hatching enzyme from the medaka larvae around hatching. Similarly, cortisol treatment was shown to accelerate hatching time in damselfish, leading to the suggestion that cortisol affected embryonic development rhythms and thereby inducing changes in the timing of hatching (Gagliano and McCormick, 2009). In zebrafish and medaka, augmenting endogenous corticosteroid levels by treating eggs with dexamethasone or cortisol advanced time of hatching, an effect which was shown to involve GR signaling pathway (Wilson et al., 2013, 2016; Nesan and Vijayan, 2013; Trayer et al., 2013). Therefore, hatching appears to be modulated in several fish species by corticosteroid hormones (cortisol and/or DOC) which underlies their physiological relevance during embryonic development.

\section{$\underline{4.5 \text { Effect of increased cortisol and DOC on CR mRNA regulation }}$}

Treatment of trout eggs with corticosteroid hormones at fertilization did not immediately affect corticosteroid receptor transcript levels (GR1, GR2 and MR) - effects of cortisol and DOC were firstly seen 2-3 weeks after exposure for all three transcripts. The more pronounced effect of DOC 
compared to cortisol on CR expressions may be related to higher DOC levels in eggs after treatment as previously discussed. Similarly to what has been discussed in the previous paragraph, we suggest that these effects on CR expression may be mediated by MR signaling pathway. This also suggests a possible connection between the high hormone levels of maternal origin at fertilization which lasts until hatching, altered regulation of corticosteroid receptors 3 weeks after mid-blastula transition, and acceleration of hatching date. Deciphering these complex regulations would require further studies which have not been developed in the present study.

\section{Conclusion}

This study is the first to describe presence of significant levels of DOC and the onset of de novo DOC synthesis in fish eggs. High DOC levels at fertilization and also just after hatching associated with significant 11 $\beta$-HSD2 expression, together with significant MR transcript levels after the midblastula transition and onwards presented here, suggest a possible physiological role for the DOCMR signaling pathway during fish ontogenesis. However, we cannot exclude the possibility that cortisol may be also involved in the activity of the MR signaling pathway - especially after the eyed stage. Both DOC and cortisol possess the potential of regulating hatching of trout eggs which underlines the physiological relevance of the MR signaling pathway in the regulation of embryonic development. Whether these effects of DOC and cortisol on hatching are related to a global acceleration of the developmental program in trout embryos or/and the regulation of hatching enzyme synthesis or activity (see review by Yamagami, 1996) would deserve further studies. Additionally, we also observe substantial regulation of GR1 and GR2 transcription during development from fertilization to hatching and effects of cortisol on regulation of CRs, although less potent compared DOC-MR. Thus, the results presented in this study, lead us to suggest that the DOC-MR signaling pathway is a functional and relevant member of the corticosteroid signaling 
system in fish aside the more established cortisol-GR axis. In conclusion, both DOC and cortisol possess the potential of regulating hatching of trout eggs which underlines the physiological relevance of the corticosteroids in embryonic development. Whether these effects of DOC and cortisol on hatching are related to a global acceleration of the developmental program in trout embryos or/and the regulation of hatching enzyme synthesis or activity (see review by Yamagami, 1996) would deserve further studies.

\section{Declaration of interests}

The authors declare that there is no conflict of interest that could be perceived as prejudicing the impartiality of the research project.

\section{Funding}

PK was supported by a postdoctoral grant from the Danish National Research Council (09-065881).

We thank Dr. Isabelle Leguen for constructive discussion during the preparation of this manuscript. 


\section{Reference list}

[1] D. Alsop, M.M. Vijayan, Development of the corticosteroid stress axis and receptor expression in zebrafish, Am. J. Physiol. Regul. Integr. Comp. Physiol. 294 (2008) R711-9.

[2] B. Auperin, M. Geslin, Plasma cortisol response to stress in juvenile rainbow trout is influenced by their life history during early development and by egg cortisol content, Gen. Comp. Endocrinol. 158 (2008) 234-9.

[3] Balment RJ, Henderson IW, Secretion of endocrine glands and their relationship to osmoregulation. In: Chester-Jones I, Ingleton PM, Phillips JG, eds. Fundamentals of comparative vertebrate endocrinology. New York: Plenum Press; 413-510 (1987)

[4] M. Bonislawska, K. Formicki, A. Korzelecka-Orkisz, A. Winnicki, Fish egg size variability: biological significance, Electronic Journal of Polish Agricultural Universities, Fisheries 4 (2001) Unpaginated.

[5] E. Bonnet, A. Fostier, J. Bobe, Characterization of rainbow trout egg quality: a case study using four different breeding protocols, with emphasis on the incidence of embryonic malformations, Theriogenology 67 (2007) 786-94.

[6] N.R. Bury, A. Sturm, P. Le Rouzic, C. Lethimonier, B. Ducouret, Y. Guiguen, M. RobinsonRechavi, V. Laudet, M.E. Rafestin-Oblin, P. Prunet, Evidence for two distinct functional glucocorticoid receptors in teleost fish, J. Mol. Endocrinol. 31 (2003) 141-56.

[7] J.G. Cloud, Deoxycorticosterone-induced precocious hatching of teleost embryos, J. Exp. Zool. 216 (1981) 197-199.

[8] Colson V, Valotaire C, Geffroy B \& Kiilerich P (2015). Egg cortisol exposure enhances fearfulness in larvae and juvenile rainbow trout. Ethology. 121 (2015) 1191-1201 
[9] S.A. Cruz, P.L. Chao, P.P. Hwang, Cortisol promotes differentiation of epidermal ionocytes through Foxi3 transcription factors in zebrafish (Danio rerio), Comp. Biochem. Physiol. A Mol. Integr. Physiol. 164(1) (2013) 249-57.

[10] M.S. Eriksen, A. Espmark, B.O. Braastad, R. Salte, M. Bakken. Long-term effects of maternal cortisol exposure and mild hyperthermia during embryogeny on survival, growth and morphological anomalies in farmed Atlantic salmon Salmo salar offspring, J. Fish Biol., 70 (2007), pp. $462-473$

[11] M. Gagliano, M.I. McCormick, Hormonally mediated maternal effects shape offspring survival potential in stressful environments, Oecologia 160 (2009) 657-65.

[12] Geffroy B \& Simon, O.. Effects of a Spirulina platensis-based diet on zebrafish female reproductive performance and larval survival rate. Cybium 37 (2013) (1-2), 31-38

[13] J.M. Hillegass, C.M. Villano, K.R. Cooper, L.A. White, Glucocorticoids alter craniofacial development and increase expression and activity of matrix metalloproteinases in developing zebrafish (Danio rerio), Toxicol. Sci. 102 (2008) 413-24.

[14] E.G. de Jesus, Y. Inui, T. Hirano, Cortisol enhances the stimulating action of thyroid hormones on dorsal fin-ray resorption of flounder larvae in vitro, Gen.Comp. Endocrinol. 79 (1990) 167-73.

[15] E.G. de Jesus, T. Hirano, Y. Inui, Changes in cortisol and thyroid hormone concentrations during early development and metamorphosis in the Japanese flounder, Paralichthys olivaceus, Gen.Comp. Endocrinol. 82 (1991) 369-76.

[16] Jiang JQ, Young G, Kobayashi T \& Nagahama Y,Eel (Anguilla japonica) testis 11betahydroxylase gene is expressed in interrenal tissue and its product lacks aldosterone synthesizing activity. Molecular and Cellular Endocrinology 146 (1998) 207-211.

[17] Kiilerich P, Servili A, Péron S, Valotaire C, Goardon L, Leguen I, Prunet P. 
Regulation of the corticosteroid signaling system in rainbow trout HPI axis during confinement stress. Gen Comp Endocrinol. S0016-6480 (2017)30176-4

[18] P. Kiilerich, C.K. Tipsmark, R.J. Borski, S.S. Madsen, Differential effects of cortisol and 11deoxycorticosterone on ion transport protein mRNA levels in gills of two euryhaline teleosts, Mozambique tilapia (Oreochromis mossambicus) and striped bass (Morone saxatilis), J. Endocrinol. 209 (2011a) 115-26.

[19] P. Kiilerich, S.H. Pedersen, K. Kristiansen, S.S. Madsen SS, Corticosteroid regulation of $\mathrm{Na}(+), \mathrm{K}(+)$-ATPase $\alpha 1$-isoform expression in Atlantic salmon gill during smolt development, Gen.Comp. Endocrinol. 70 (2011b) 283-9.

[20] P. Kiilerich, S. Milla, A. Sturm, C. Valotaire, S. Chevolleau, F. Giton, X. Terrien, J. Fiet, A. Fostier, L. Debrauwer, P. Prunet, Implication of the mineralocorticoid axis in rainbow trout osmoregulation during salinity acclimation, J. Endocrinol. 209 (2011c) 221-35.

[21] M.A. Kim, D.S. Kim, Y.C. Sohn, Characterization of two functional glucocorticoid receptors in the marine medaka Oryzias dancena, Gen. Comp. Endocrinol. 171(3) (2011) 341-9.

[22] W. Kloas, M. Reinecke, W. Hanke, Stage-dependent changes in adrenal steroids and catecholamines during development in Xenopus laevis, Gen.Comp. Endocrinol. 108 (1997) 416-26.

[23] M. Li, D.P. Bureau, W.A. King, J.F. Leatherland, The actions of in ovo cortisol on egg fertility, embryo development and the expression of growth-related genes in rainbow trout embryos, and the growth performance of juveniles, Molecular Reproduction and Development 77 (2010) 922-31.

[24] S.D. McCormick, Endocrine control of osmoregulation in teleost fish, Am. Zool. 41 (2001) 781-794.

[25] S.D. McCormick, A. Regish, M.F. O'Dea, J.M. Shrimpton, Are we missing a mineralocorticoid in teleost fish? Effects of cortisol, deoxycorticosterone and aldosterone on osmoregulation, gill 
$\mathrm{Na}+\mathrm{K}+-$ ATPase activity and isoform mRNA levels in Atlantic salmon, Gen.Comp. Endocrinol. 157 (2008) 35-40.

[26] S. Milla, N. Wang, S.N. Mandiki, P. Kestemont, Corticosteroids: Friends or foes of teleost fish reproduction? Comp. Biochem. Physiol., Part A Mol. Integr. Physiol. 153 (2009) 242-51.

[27] T.P. Mommsen, M.M. Vijayan, T.W. Moon, Cortisol in teleosts: dynamics, mechanisms of action, and metabolic regulation, Rev. Fish Biol. Fish. 9 (1999) 211-268.

[28] D. Nesan, D., Kamkar, M., Burrows, J., Scott, I.C., Marsden, M., M.M Vijayan. Glucocorticoid receptor signaling is essential for mesoderm formation and muscle development in zebrafish. Endocrinology 153 (2012) 1288-1300.

[29] D. Nesan, M.M. Vijayan, Role of glucocorticoid in developmental programming: Evidence from zebrafish, Gen.Comp. Endocrinol. 181 (2013) 35-44 .

[30] M. Pavlidis, E. Karantzali, E. Fanouraki, C. Barsakis, S. Kollias, N. Papandroulakis, Onset of the primary stress in European sea bass Dicentrarhus labrax, as indicated by whole body cortisol in relation to glucocorticoid receptor during early development, Aquaculture 315 ( 2011) 125-130.

[31] S. Pikulkaew, A. De Nadai, P. Belvedere, L. Colombo, L. Dalla Valle, Expression analysis of steroid hormone receptor mRNAs during zebrafish embryogenesis, Gen.Comp. Endocrinol. 165 (2010) 215-20.

[32] S. Pikulkaew, F. Benato, A. Celeghin, C. Zucal, T. Skobo, L. Colombo, L. Dalla Valle, The knockdown of maternal glucocorticoid receptor mRNA alters embryo development in zebrafish, Dev. Dyn. 240 (2011) 874-89.

[33] P. Prunet, A. Sturm, S. Milla, Multiple corticosteroid receptors in fish: from old ideas to new concepts, Gen.Comp. Endocrinol. 147(1) (2006) 17-23.

[34] R Development Core Team. R: A language and environment for statistical computing, R Foundation for Statistical Computing, Vienna, Austria (2009), http://cran.r-project.org/ 
[35] Ritz C. \& Streibig J.C. Bioassay analysis using R. J. Stat. Soft., 12( 2005.) 1-22.

[36] K. Rousseau, S. Aroua, M. Schmitz, P. Elie, S. Dufour, Silvering: Metamorphosis or Puberty? In Spawning migration of the European Eel, van den Thillart et al. eds. Springer Publisher, (2008) pp 39-63.

[37] Sakamoto T, Yoshiki M, Takahashi H, Yoshida M, Yukiko Ogino Y,Ikeuchi T, Nakamachi T, Konno N, Matsuda K, Sakamoto H. Principal function of mineralocorticoid signaling suggested by constitutive knockout of the mineralocorticoid receptor in medaka fish. Sci Rep 6, (2016) 37991 [37] [38] M.J. Schaaf, D. Champagne, I.H. van Laanen, D.C. van Wijk, A.H. Meijer, O.C. Meijer, H.P. Spaink, M.K. Richardson, Discovery of a functional glucocorticoid receptor beta-isoform in zebrafish, Endocrinology 149 (2008) 1591-9.

[39] K.A. Sloman, Exposure of ova to cortisol pre-fertilisation affects subsequent behaviour and physiology of brown trout, Horm. Behav. 58 (2010) 433-9.

[40] A. Sturm, N. Bury, L. Dengreville, J. Fagart, G. Flouriot, M.E. Rafestin-Oblin, P. Prunet, 11deoxycorticosterone is a potent agonist of the rainbow trout (Oncorhynchus mykiss) mineralocorticoid receptor, Endocrinology 146 (2005 ) 47-55.

[41] M. Tagawa, H. Hagiwara, A. Takemura, S. Hirose, T. Hirano, Partial cloning of the hormonebinding domain of the cortisol receptor in tilapia, Oreochromis mossambicus, and changes in the mRNA level during embryonic development, Gen.Comp. Endocrinol. 108 (1997) 132-40.

[42] Takahashi, H. \& Sakamoto, T. The role of 'mineralocorticoids' in teleost fish: relative importance of glucocorticoid signaling in the osmoregulation and 'central' actions of mineralocorticoid receptor. Gen Comp Endocrinol 181(2013) 223-228.

[43] Trayer V, Hwang PP, Prunet P, Thermes V. Assessment of the role of cortisol and corticosteroid receptors in epidermal ionocyte development in the medaka (Oryzias latipes) embryos. Gen Comp Endocrinol. 194 (2013)152-61. 
[44] S. Viengchareun, D. Le Menuet, L. Martinerie, M. Munier, L. Pascual-Le Tallec, M. Lombès, The mineralocorticoid receptor: insights into its molecular and (patho)physiological biology, Nucl. Recept. Signal. 5 (2007) e012.

[45] K.S. Wilson, G. Matrone, D.E. Livingstone, E.A.S. Al-Dujaili, J.J. Mullins, C.S. Tucker, P.W.F. Hadoke, C.J. Kenyon, M.A. Denvir. Physiological roles of glucocorticoids during early embryonic development of the zebrafish (Danio rerio). J. Physiol. 591 (2013) 6219-6220.

[46] K.S. Wilson, C.S. Tucker, E.A.S. Al-Dujaili, M.C. Holmes, P.W.F., Hadoke, C.J. Kenyon, M.A. Denvir. Early-life glucocorticoids programme behaviour and metabolism in adulthood in zebrafish. J. Endocrinol. 230 (2016) 125-142.

[47] K. Yamagami, Studies on the hatching enzyme (choriolysin) and its substrate, egg envelope, constructed of the precursors (choriogenins) in Oryzias latipes: a sequel to the information in 1991/1992, Zoolog. Sci. 13 (1996) 331-40.

[48] Young, E. A., Abelson, J., \& Lightman, S. L. Cortisol pulsatility and its role in stress regulation and health. Frontiers in neuroendocrinology, 25(2004) 69-76. 


\section{Figure legends}

Figure 1: Whole egg mRNA transcript levels of proteins involved in DOC synthesis : (A) StAR

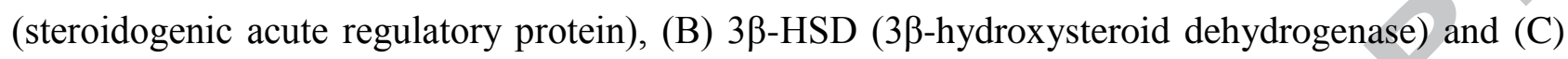
CYP21 (21-hydroxylase). Overall effect of time was detected by one-way ANOVA for all transcripts $(\mathrm{p}<0.0001)$. Values with no letters in common are significantly different as determined by multiple t-tests with Bonferroni correction (mean \pm SEM, $n=8$ ).

Figure 2: Whole egg mRNA transcript levels of (A) MR, (B) GR1, (C) GR2 and (D) 11ß-HSD2 from fertilization to the swim-up stage. Overall effect of time was detected by one-way ANOVA for MR, GR1, 11 $\beta$-HSD2 ( $<<0.0001)$ and GR2 ( $\mathrm{p}<0.0005)$. Values with no letters in common are significantly different as determined by multiple t-tests with Bonferroni correction (mean $\pm \mathrm{SEM}$, $\mathrm{n}=8)$.

Figure 3: Whole egg DOC concentration during embryogenesis from fertilization to the swim-up stage (mean \pm SEM, $n=10)$. There is an overall effect on time $(\mathrm{p}<0.0001)$ as detected by one-way ANOVA and values with no letters in common are significantly different as determined by multiple t-tests with Bonferroni correction. MBT - midblastula transition.

Figure 4: Regulation of (A) MR, (B) GR1 and (C) GR2 transcript levels from fertilization to day 27 after in ovo DOC or cortisol treatment. There is no overall significant effect of DOC or cortisol treatment on MR transcript levels as determined by two-way ANOVA but there was a significant interaction between treatment and time which led us to carry out Bonferroni corrected pairwise comparisons at each time point. Overall significant effect of DOC and cortisol on GR1 transcript levels ( $\mathrm{p}<0.0005$ and $\mathrm{p}<0.05$, respectively) was detected along with an overall effect of DOC on 
GR2 transcript levels $(\mathrm{p}<0.05)$ and significant difference between DOC and cortisol treatment for GR2 ( $\mathrm{p}<0.05)($ mean \pm SEM, $n=8)$. A star denotes significant difference from control and \# denotes significant difference between cortisol and DOC groups at different time points as determined by Bonferroni corrected pairwise comparisons.

Figure 5: Number of malformations at the swim-up stage and survey of hatching date after hormone treatment at fertilization. (A) The percentage of malformed fry at the swim-up stage (55 dpf) in DOC and cortisol treated eggs. YSD - yolk sac resorption defects. There was no effect of either treatment compared to control as determined by two-way ANOVA $(\mathrm{p}>0.05)$ (mean \pm SEM, $n=4)$. (B) Effect of DOC and cortisol on hatching date is depicted as percentage of the total number of hatched embryos. There is an overall effect of DOC ( $p<0.0001)$ and cortisol $(p<0.0001)$ compared to control and an overall effect of DOC compared to cortisol $(\mathrm{p}<0.0001)$ as determined by two-way ANOVA. A star denotes significant difference from control and \# denotes significant difference between cortisol and DOC groups as determined by multiple t-tests with Bonferroni correction (mean \pm SEM, $\mathrm{n}=4$ ). 

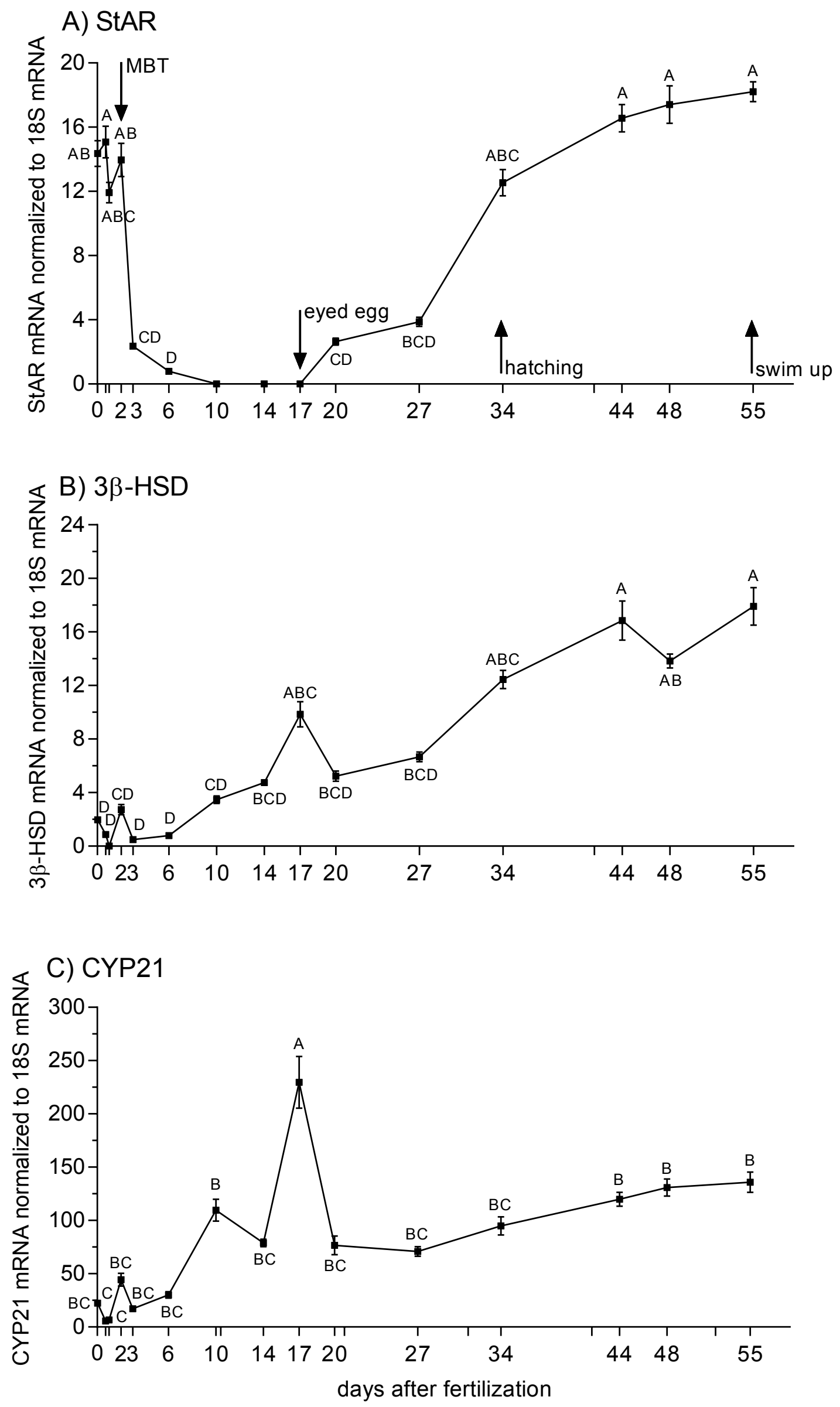
A) $M R$

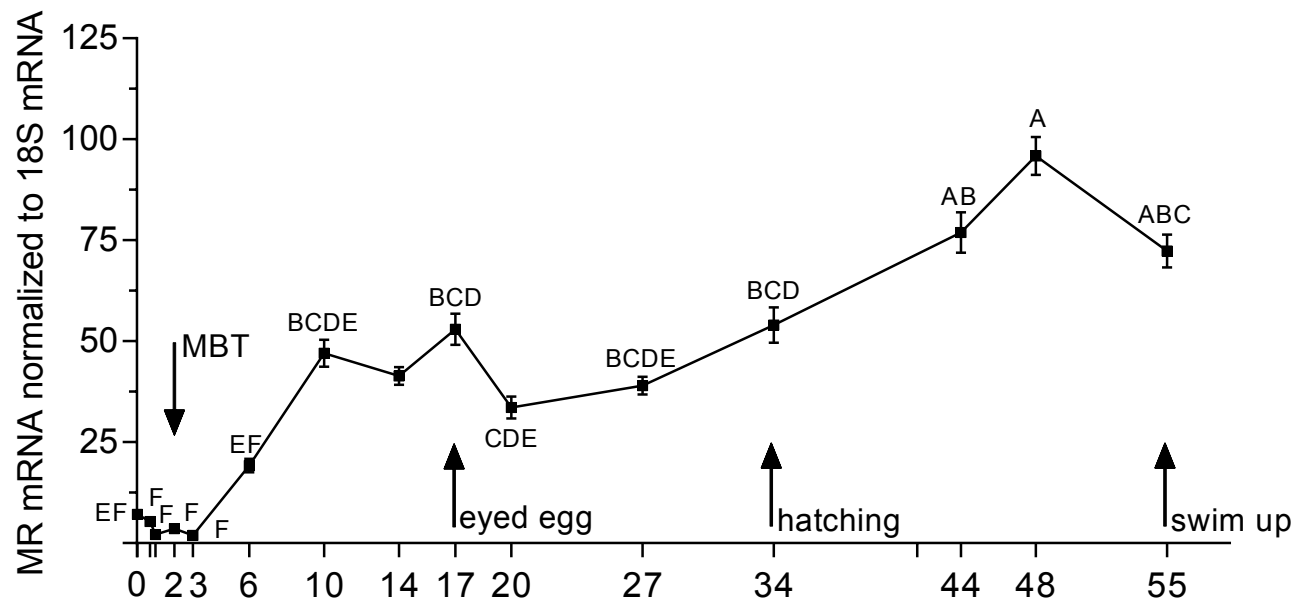

B) GR1

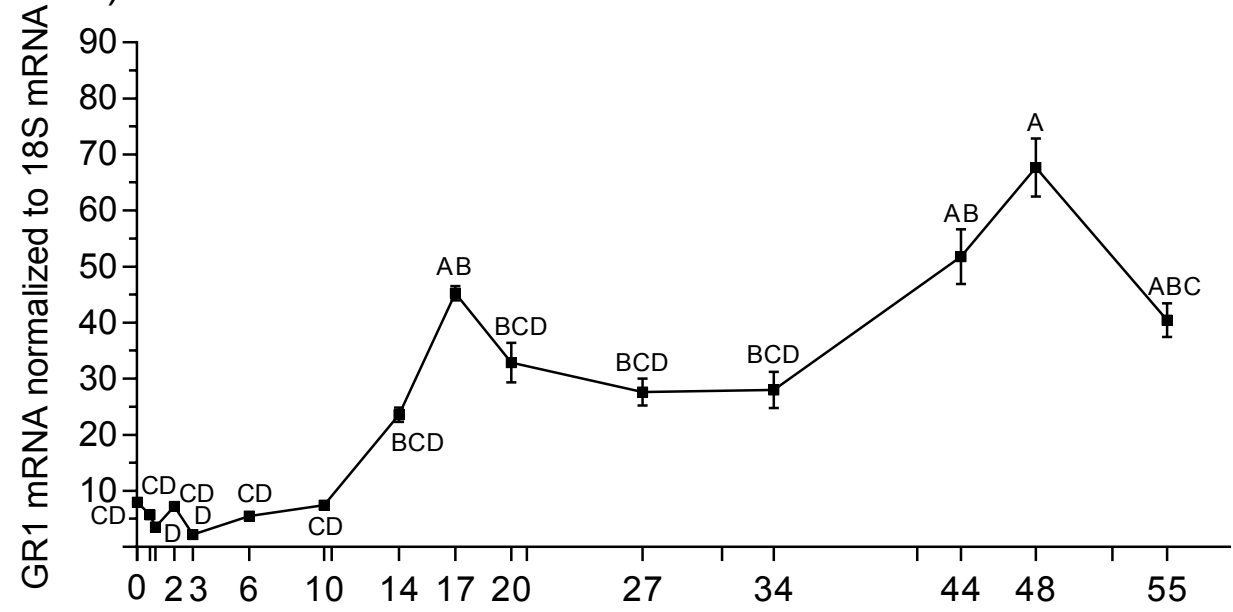

C) GR2
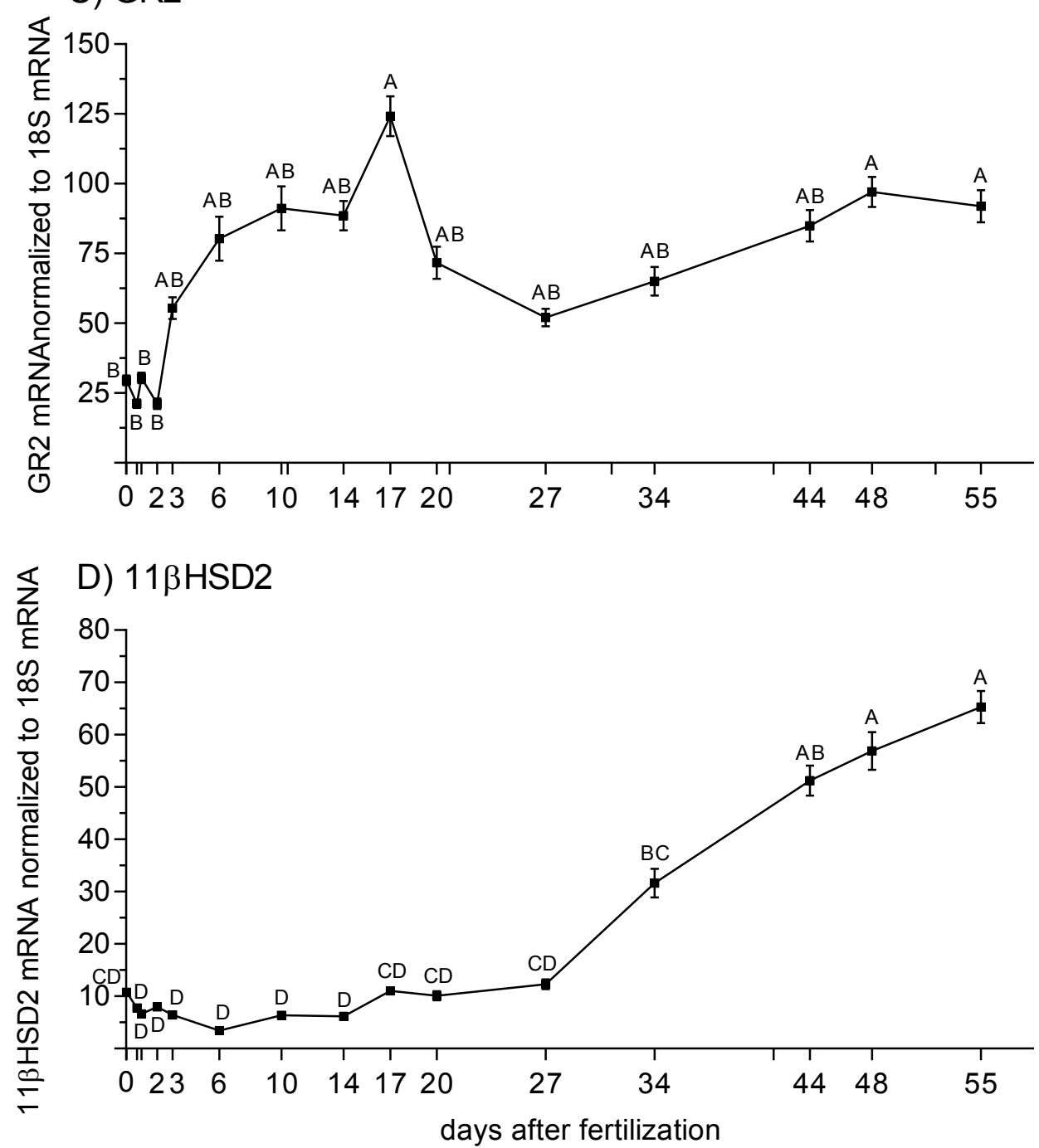


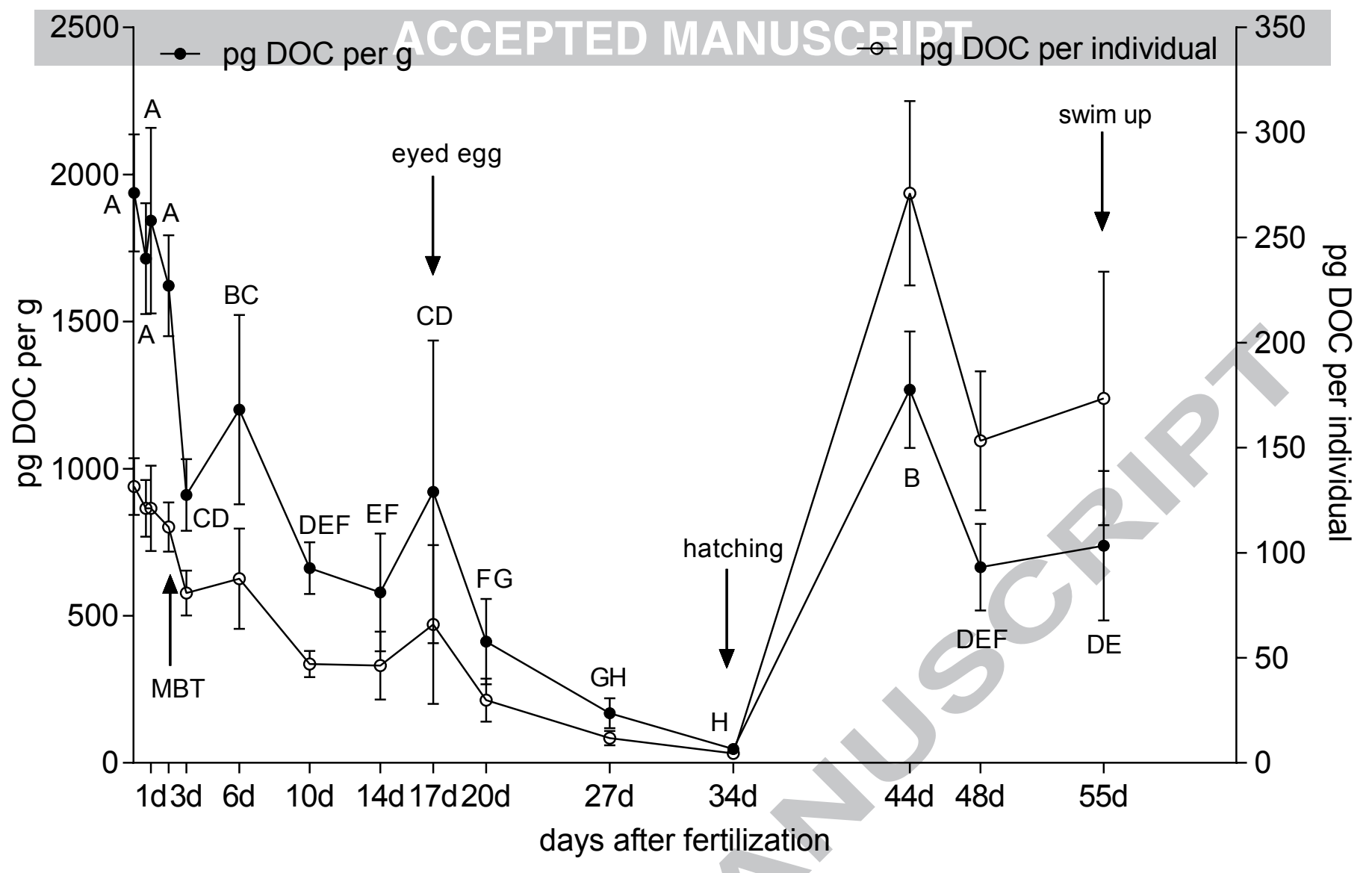


A) MR

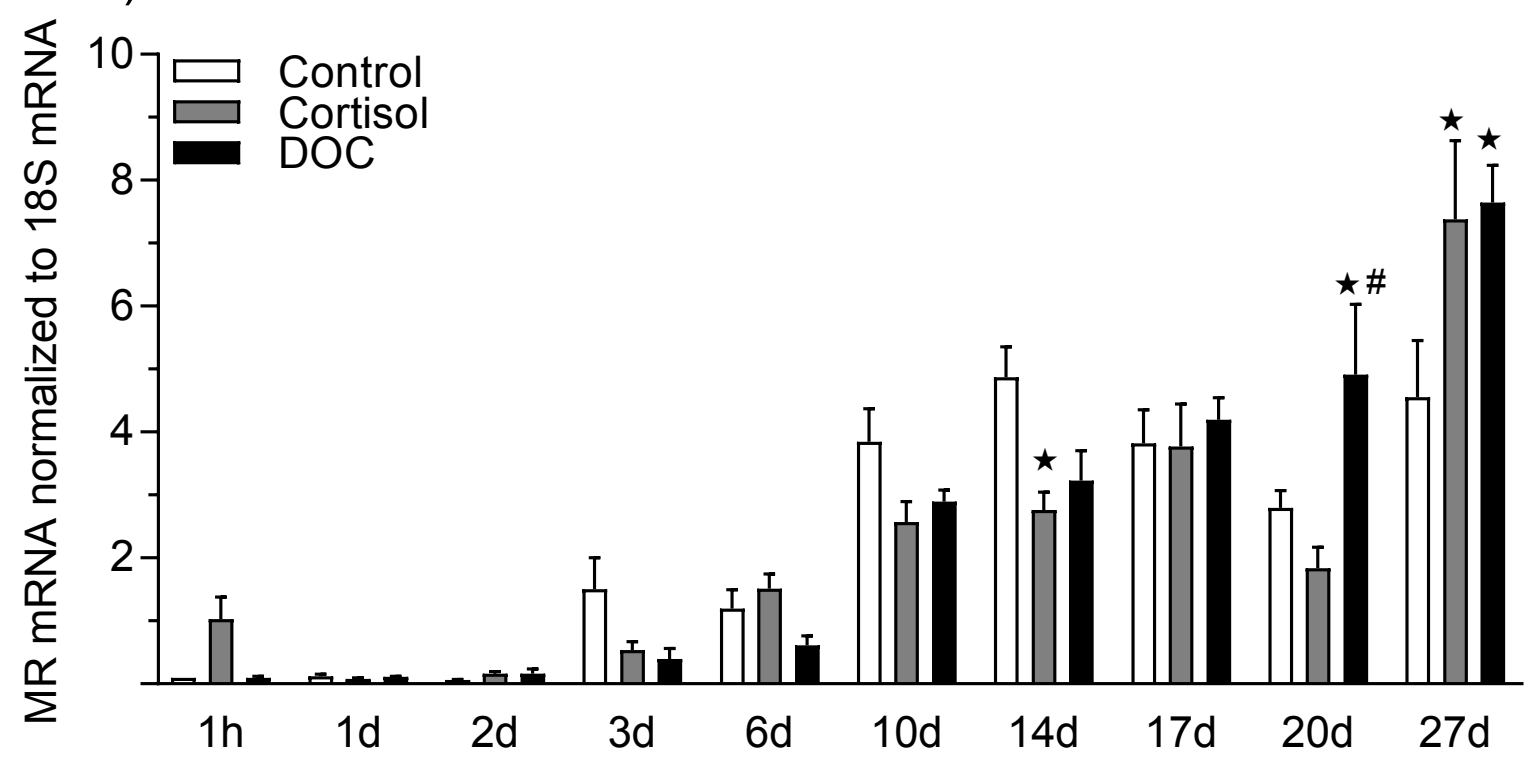

B) GR1

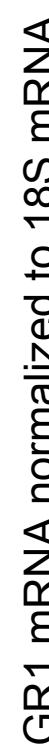

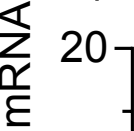

\begin{tabular}{ll}
$\infty$ & $16-$ \\
\hdashline
\end{tabular}

웅 $12-$

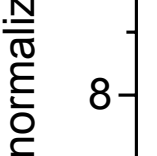

这

C) GR2

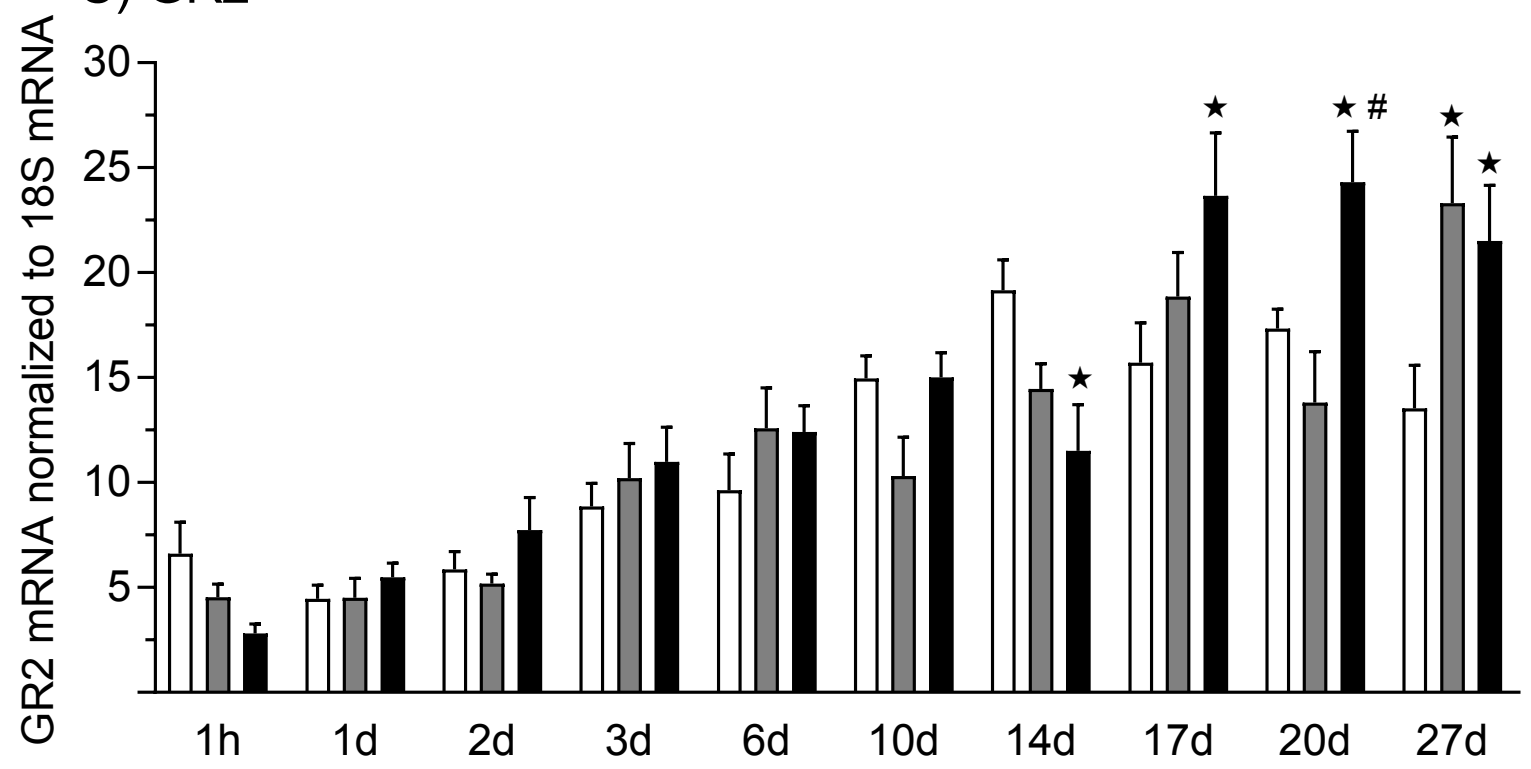


A)

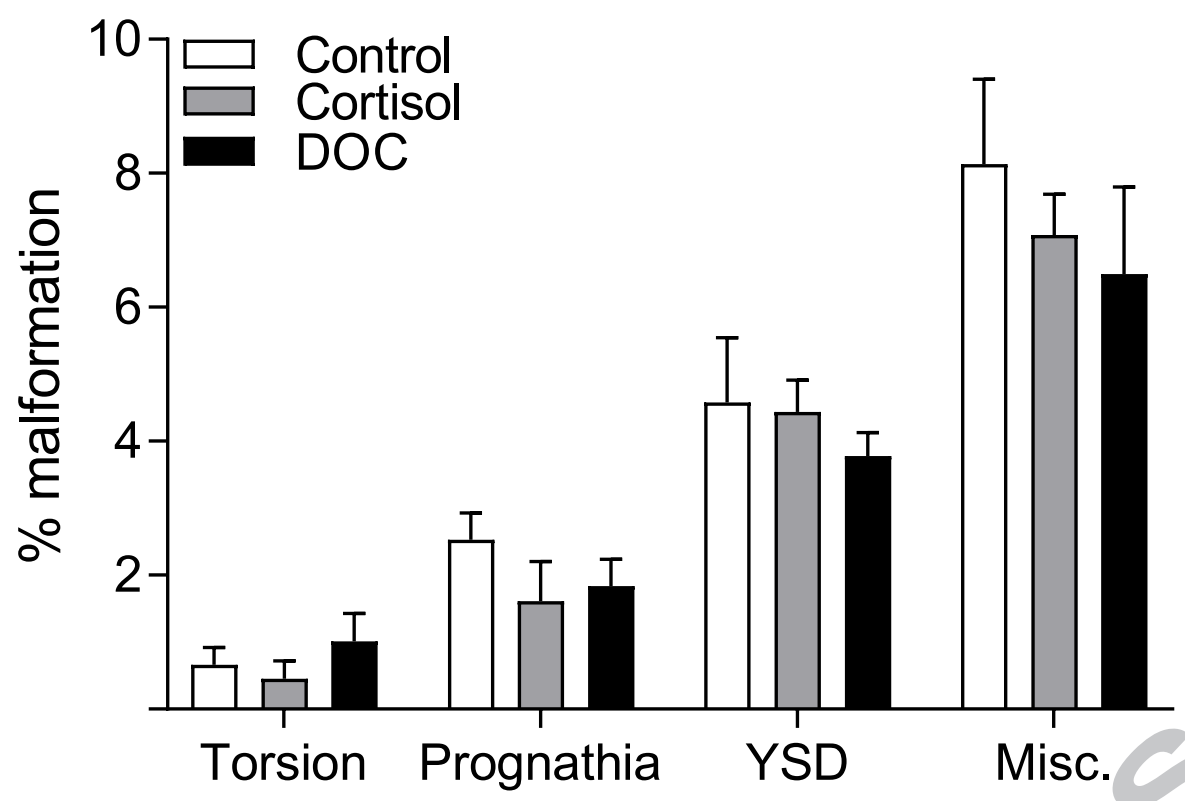

B)

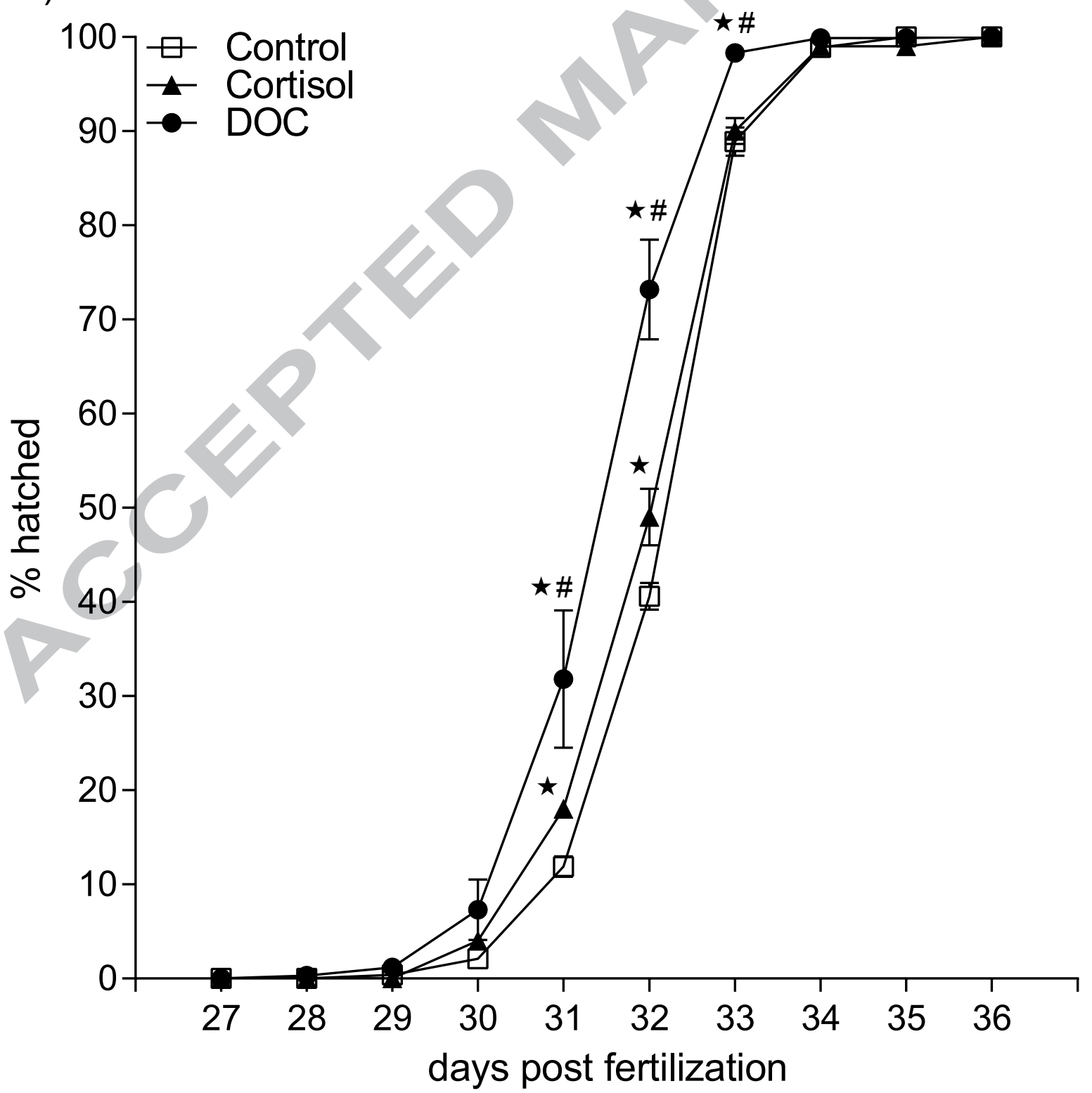

